\title{
USING SIMULATION AND DATA ENVELOPMENT ANALYSIS IN OPTIMAL HEALTHCARE EFFICIENCY ALLOCATIONS
}

\author{
Shao-Jen Weng \\ Bo-Shiang Tsai \\ Tunghai University \\ Department of Industrial Engineering and \\ Enterprise Information \\ Taichung, TAIWAN 407 (R.O.C)
}

\author{
Lee-Min Wang \\ Chun-Yueh Chang \\ Taichung Veterans General Hospital \\ Emergency Department \\ Taichung, TAIWAN 407 (R.O.C)
}

\author{
Donald Gotcher \\ Tunghai University \\ Department of International Business \\ Taichung, TAIWAN 407 (R.O.C)
}

\begin{abstract}
As in many other parts of the world, overcrowding in Taiwan's hospital Emergency Departments (ED) is an increasingly scrutinized area. EDs in Taiwan hospitals must implement efficient systems that minimize costs while also providing satisfactory levels of care. The primary goal of this investigation is to develop and deploy a mixed method incorporating Discrete Event Simulation (DES) and Data Envelopment Analysis (DEA) to evaluate potential bottlenecks, maximize throughput flows, and identify solutions in reducing patient time in the ED while also increasing patient satisfaction. Hospital administrators can use the model data as a realistic reproduction to evaluate different scenarios and make modifications which best fit hospital operations. This paper incorporates various types of ED resources as inputs including: number of physicians, number of nurses, and number of beds. We assessed the impact of changing levels of these inputs on ED operation efficiency, with optimal efficiency resource allocations as the goal.
\end{abstract}

\section{INTRODUCTION}

Emergency Department crowding, a consequence of simultaneous increasing demand for health care and a deficit in available hospital beds and ED beds, has become an increasingly significant public health problem (Derlet 2002; Fatovich, Nagree, and Sprivulis 2005; Twanmnoh and Cunningham 2006; Ackermann et al. 1998). ED crowding has been associated with negative effects, including adverse patient outcomes (such as long wait times, reduced quality of care treatment delays, and increased numbers of patients who leave without being seen), as well as detrimental financial effects (Hoot and Aronsky 2008).

Crowding is a problem in the US where one study found it occurs $12 \%-73 \%$ of the time (Weiss et al. 2004) and it is also a global problem (Yoon, Steiner, and Reinhardt 2003). Significant overcrowding also exists in Taiwan (Shih et al. 1999); consequently, great efforts are being made by the administrators of EDs to consider patient satisfaction as a relevant factor (along with the medical treatment they receive) when addressing ED overcrowding. 


\section{Weng, Tsai, Wang, Chang, and Gotcher}

Over the past decade, researchers have taken advantage of the power of simulation technology to develop models that can be fully integrated into complex systems and run in real-time. Examples include the control and analysis of manufacturing and scheduling (Tavakoli, Mousavi, and Komashie 2008). In these instances, the gain in system performance as a result of the use of simulation has been noticeable. For example, Wu and Wysk (1988) found significant improvements using a simulation model to determine the future course for a manufacturing system.

For this paper, we propose using a mixed approach combining two methods: Discrete Event Simulation (DES) and Data Envelopment Analysis (DEA) to assess operational efficiency. The reasons for this mixed hybrid approach are (1) the complexity of healthcare systems, where DES has proved to be an effective tool for process improvement (Khurma, Bacioiu, and Pasek 2008; Duguay and Chetouane 2007) and (2) the relative efficiency of a group of ED operations or decision-making units (DMUs) using multiple inputs to produce multiple outputs where the form of production is not known or specified, with respect to hospitals, DEA has been shown to be an effective tool for measuring efficiency in healthcare with applications dating back to the 1980s (Grosskopf and Valdmanis 1987, Wilson and Jadlow 1982, Nunamaker 1983, Sherman 1984).

\section{LITERATURE REVIEW}

Multiple studies in the literature have been aimed at reducing waiting times and increasing service levels (throughput) by improving the actual process (Barnes and Laughery 1998). In recent years, the use of simulation based studies has been extended to answer "what if" questions in an attempt to design more efficient healthcare services (Jun, Jacobson, and Swisher 1999). Due to their complex and stochastic nature, simulation is used as a tool to analyze critical parts of healthcare systems such as facility design (emergency departments, operating rooms, etc.), staff planning and scheduling, and bed capacity management (Yurtkuran and Emel 2008). Using DES, Komashie and Mousavi (2005) conducted a study of an ED in a British hospital, with the objective of determining the impact of key resources (waiting times, waiting lines, and throughput). DES is useful in a healthcare setting for the following rationale: Crowding is a complex phenomenon that can be summarized by numerous different measures, such as the number of waiting patients, boarding patients, or occupied beds. Most other forecasting techniques require the investigator to select a dependent variable before model development; by contrast, DES can output a detailed list of patients projected to be in the ED in the future, and from this information the forecasts of outcome measures can be derived (Hoot et al. 2009). Thus, DES is not only about data collection and output analysis, it also involves learning the complexity of the system and designing a valid model that is useful for training and decision-making (Duguay and Chetouane 2007).

DEA, which was developed by Charnes, Cooper, and Rhodes (1978), maximizes each DMU's own measured efficiency relative to other DMUs. DEA compares the efficiency of organizational units such as bank branches, store outlets, governmental departments, and schools in which there is a relatively homogenous set of units (Ertay, Ruan, and Tuzkaya 2006). DEA is a mathematical programming model used to evaluate the relative efficiency of a group of entities or decision-making units (DMUs) using multiple inputs to produce multiple outputs where the form of production is not known or specified. Advantages of using DEA include: 1) the ability to assume a deterministic relationship between inputs and outputs and its ease in estimating the efficiency scale (Grosskopf and Valdmanis 1993); 2) The ability to handle multiple inputs and multiple outputs simultaneously without requiring an assumption of a functional form relating inputs to output (as regression methods do) (Sexton 1986; Thanassoulis 1993; Osei, D'Almeida, and George 2005), and 3) The ability to compare against a peer or combination of peers at the same time even without sensitive information such as prices (Osei, D'Almeida, and George 2005).

Since ED is a complex system, we can't use purely mathematical models such as linear programming, non-linear programming or others for solving problems. The best method is discrete event simulation. It can be used in solving "what-if" healthcare resource allocation problems because it can deal with a dynamic healthcare system and with complex interactions among various components and processes. Moreover, DEA can evaluate the different DMUs, and include multiple inputs and outputs. Further, DEA 
gives an efficiency index which has been used in healthcare evaluation for the past three decades. Thus, we propose this mixed method for examining the issue.

\section{SIMULATION MODEL DEVELOPMENT AND DATA COLLECTION}

An ED simulation model was developed involving a cooperative effort at a large teaching hospital research center in Taiwan over a year period. We developed the model with a preexisting data set, along with institutional information and expert clinician input. The ED department has a 53 non-trauma bedcapacity in the ED, divided into three individual areas. Specifically, these are: the Resuscitation Room (RM), with 8 beds reserved for critical care; the Main Emergency Department (MED), with 5 fixed beds and the Observation Unit (OU), with 40 assigned to the OU in the back of the ED. The RM treats patients needing to see a physician immediately, whereas the MED deals with less-severe conditions. OU patients stay for other treatments or lab tests after 6 hours of waiting.

During the study period, attending physicians staffed the main emergency department (MED) during different shifts. The staffing levels and available resources used in the model are summarized in Table 1. For example, two physicians (PHs), two PHs, and one PH staffed the ED-RR from 8:00 AM to 4:00 PM, 4:00 PM to 12:00 AM, and 12:00 AM to 8:00 AM, respectively. The ED directs different proportions of patients to home, hospital, and the observation unit based on the patient dispatch distribution (Table 2). Thus, our research placed emphasis on three dispatch situations: discharge, admitted, and observed patients, and our goal was to find the mix of physicians, nurses, and beds to achieve efficiencies; that is, for each shift period, what number of PHs, nurses, and beds in the RR, TS, MED, and OU would maximize efficiency.

Table 1: Staffing levels and available resources

\begin{tabular}{|l|l|l|l|}
\hline & $\mathrm{PH}$ & Nurse & Bed \\
\hline Resuscitation Room (RR) & ${ }^{\mathrm{A}} 1 /{ }^{\mathrm{B}} 2 /{ }^{\mathrm{C}} 2$ & $2 / 2 / 2$ & 8 \\
\hline Triage Station (TS) & & $1 / 1 / 1$ & - \\
\hline Main Emergency Department (MED) & $2 / 4 / 3$ & $2 / 3 / 3$ & 5 \\
\hline Observation Unit (OU) & $1 / 2 / 2$ & $3 / 4 / 4$ & 40 \\
\hline
\end{tabular}

Note: $\mathrm{A} / \mathrm{B} / \mathrm{C}$ is Night shift/Day shift/Evening shift

Table 2: Patient dispatching distribution after MED

\begin{tabular}{|l|l|l|l|l|}
\hline & TTS 1 & TTS 2 & TTS 3 & TTS 4 \\
\hline Discharge & $12.83 \%$ & $44.85 \%$ & $60.13 \%$ & $50.00 \%$ \\
\hline Admitted & $20.32 \%$ & $3.33 \%$ & $5.47 \%$ & $0.00 \%$ \\
\hline Observed & $63.10 \%$ & $51.82 \%$ & $34.41 \%$ & $50.00 \%$ \\
\hline Dead & $3.74 \%$ & $0.00 \%$ & $0.00 \%$ & $0.00 \%$ \\
\hline
\end{tabular}

We used patient ED visit data from January 2009 to December 2009 as the benchmark figure, including 32,139 total ED visit codes with a mean of 89 visits per day. The patient arrival pattern over a 24-h period in our study (Figure 1) is valid based on data collected from a study conducted at 163 Canadian Hospitals (Oviatt and Hollingsworth 2005). The probability distribution of daily patient arrivals is fitted using an ARENA input analyzer. For the simulation model, patient arrival times during the seven-day study period were used to create an exponential distribution of patient interarrival time. Interarrival time is the time between consecutive patient arrivals. The exponential distribution is the standard distribution to use for fitting interarrival times. Thus, the time between consecutive occurrences of patients has assumed an exponential distribution. 
Weng, Tsai, Wang, Chang, and Gotcher

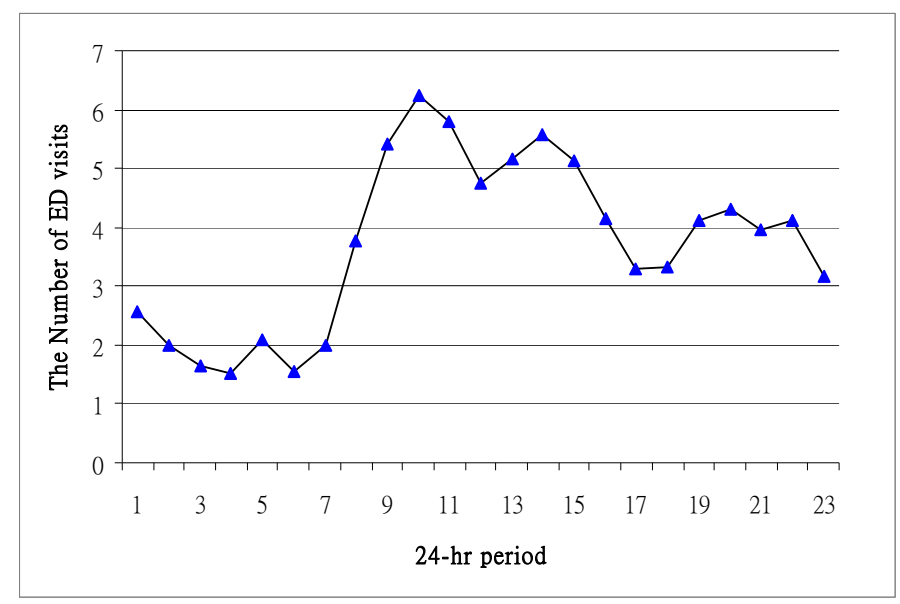

Figure 1: Patient arrival pattern over a 24-h period- October to December, 2009

When patients in the model arrive in the ED, they are assigned a Taiwan Triage Scale (TTS) priority code. The TTS is a 4-level triage system, and the ED areas use an ordinal score ranging from one, for the most urgent patients, to four, for the least urgent patients. This 4-level triage system was introduced as an indicator of ED patient acuity for National Health Insurance (NHI) ED reimbursement payments. To model the priorities of patients in the ED, we assigned the initial evaluation of all trauma and resuscitation patients the highest priority (TTS 1). Patients are then directed to the main ED or RM, depending on their TTS category. Patient flow was dispatched by the triage service according to the following proportions: $9.6 \%$ TTS $1,74.1 \%$ TTS $2,16.1 \%$ TTS 3 , and less than $1 \%$ for TTS 4 . To model the flow of patients cared for in the ED, we defined and coded the locations, resources, processes, and routing policies.

The process begins when a patient arrives at the ED and ends when he/she is either released from the ED or admitted into the hospital for further treatment. Upon arrival, the patient registers and is screened by a triage nurse and assigned a triage code. Depending on the acuity of the patient, he/she will be assigned to the RR (for triage code 1 patients) or the MED (for triage code 2, 3, and 4 patients). A doctor examines the patient and assesses whether further tests or X-rays are warranted, or whether immediate treatment can take place. Non-critical patients after receiving tests and treatment can receive medication (if any) and be discharged. Critical patients, after six hours in the ED, receive further diagnosis, and if deemed necessary, admitted to the OU. Finally, critical patients, after observation, testing, and treatment are released from the OU, or admitted to the hospital for further evaluation and treatment. The hospital would like to find the configuration of resources that maximize patient throughput (patient dismissed per unit time) subject to average wait time in the system. The following chart provides a graphic representation of the foregoing. Moreover, modeled staffing activities and associated staff estimates of average procedure times are listed in Table 3. Note that the simulation model does not include balking and reneging.

With respect to lab and treatment cycles and distribution (Table 4), $15 \%$ of TTS 1 patients requires one cycle of lab tests or/and treatments which could include blood tests, ultrasounds, portable radiography, MRI, CT, fixed radiography, or/and cardiac stress tests. $37 \%$ of TTS 1 patients need to do two cycles of lab tests or/and treatments which may include one or more labs items. 15\% of TTS 1 patients need to do three cycles of lab tests or/and treatments which may include one or more lab items. The others (11\% of TTS $1,10 \%$ of TTS $1,6 \%$ of TTS 1 , and $5 \%$ of TTS 1 ) follow the same logic mentioned before. Moreover, the TTS 2, 3, and 4 populations are matched with the same modeling logic as TTS 1 . Based on the collected observations, $30 \%$ of patients were treated once (one/more lab tests and/or drug treatments needed), $45 \%$ needed two treatments, and $25 \%$ needed more than three treatments. Thus, $45 \%$ of patients required a second/or additional assessment by the same physician ordering the tests, and $25 \%$ of patients needed three or more assessments. 


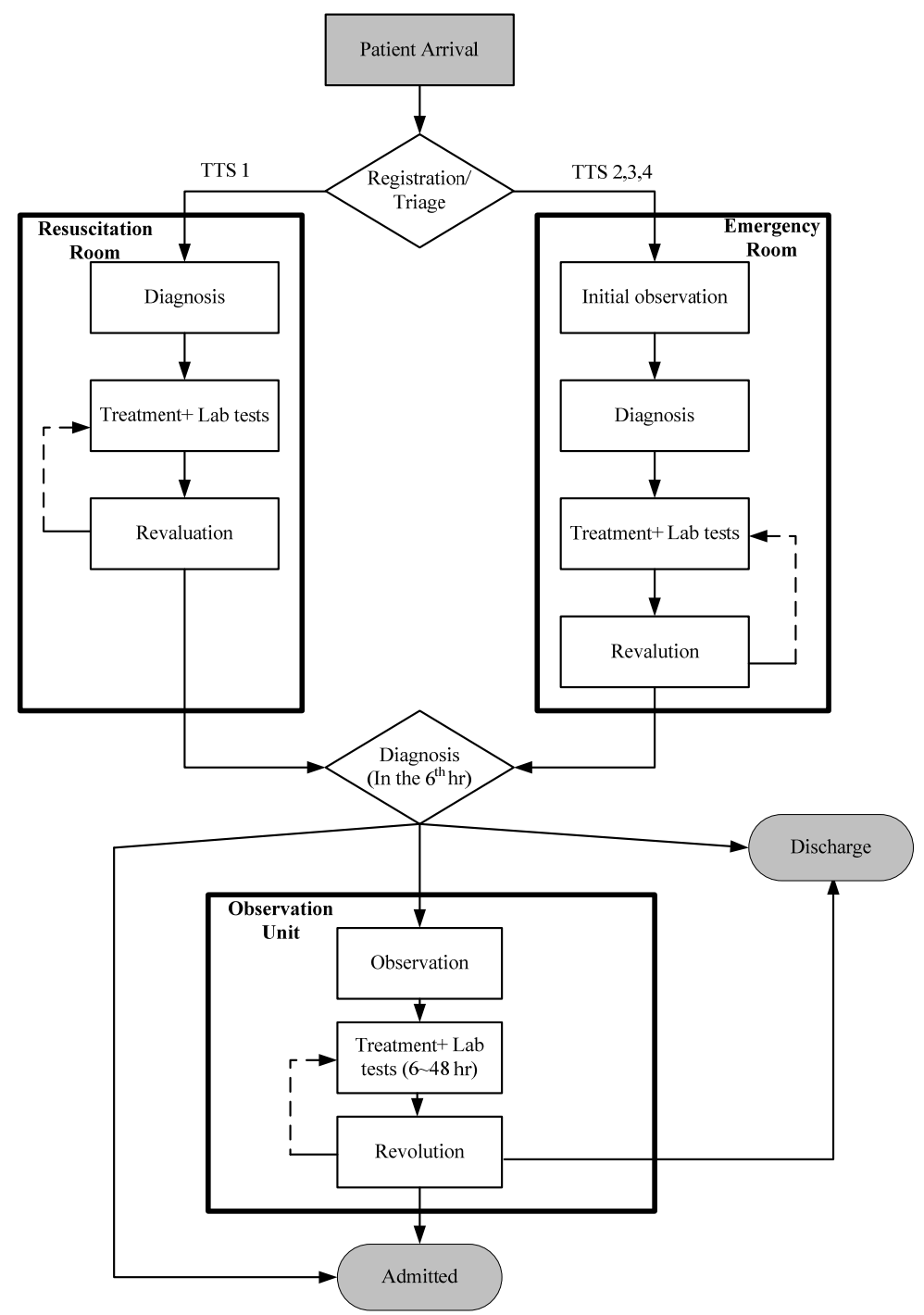

Figure 2: Generic flowchart of ED flow arrangement

Table 3: Fitting statistical distribution for each station in the model

\begin{tabular}{|c|c|}
\hline Station & Distribution (minutes) \\
\hline Patient Arrival & \\
\hline Mon & $* \operatorname{Exp}(9.71)$ \\
\hline Tue & $\operatorname{Exp}(9.47)$ \\
\hline Wed & $\operatorname{Exp}(9.85)$ \\
\hline Thu & $\operatorname{Exp}(9.96)$ \\
\hline Fri & $\operatorname{Exp}(9.02)$ \\
\hline Sat & $\operatorname{Exp}(9.45)$ \\
\hline Sun & $\operatorname{Exp}(9.63)$ \\
\hline Check-in and Triage & $* *$ Tri $(5,8,10)$ \\
\hline Diagnosis by a Nurse & $\operatorname{Exp}(5.0)$ \\
\hline Diagnosis by a $\mathrm{PH}$ & $\operatorname{Tri}(4,8,12)$ \\
\hline Revaluation by a PH & Tri $(4,8,12)$ \\
\hline
\end{tabular}


Table 4: Lab and treatment (L\&T) cycles and distribution of TTS levels

\begin{tabular}{|l|l|l|l|l|l|}
\hline L\&T Cycles & $\begin{array}{l}\text { Service } \\
\text { Time }\end{array}$ & TTS 1 & TTS 2 & TTS 3 & TTS 4 \\
\hline 1 & $\operatorname{Exp}(80)$ & $15 \%$ & $23 \%$ & $32 \%$ & $50 \%$ \\
\hline 2 & $\operatorname{Exp}(150)$ & $37 \%$ & $49 \%$ & $42 \%$ & $50 \%$ \\
\hline 3 & $\operatorname{Exp}(150)$ & $15 \%$ & $18 \%$ & $17 \%$ & $0 \%$ \\
\hline 4 & $\operatorname{Exp}(170)$ & $11 \%$ & $7 \%$ & $6 \%$ & $0 \%$ \\
\hline 5 & $\operatorname{Exp}(170)$ & $10 \%$ & $2 \%$ & $1 \%$ & $0 \%$ \\
\hline 6 & $\operatorname{Exp}(170)$ & $6 \%$ & $0 \%$ & $0 \%$ & $0 \%$ \\
\hline 7 & $\operatorname{Exp}(170)$ & $5 \%$ & $0 \%$ & $0 \%$ & $0 \%$ \\
\hline Total & & $100 \%$ & $100 \%$ & $100 \%$ & $100 \%$ \\
\hline
\end{tabular}

The main resources in the ED are defined as: Nurses, Physicians (PHs), and Beds. As noted above in Table 1, we measured varying staff levels of PHs and nurses during their shifts in an effort to identify the optimal mix. Staffing levels were tested at various stages of the ED patient flow experience: Resuscitation Room (RR), Triage Station (TS), Main Emergency Department (MED), and Observation Unit (OU). The model simulated and tracked ED patients throughout their ED stay, from presentation to discharge. It includes details of the model including data used and assumptions made for patient arrivals, triage, waiting areas, leaving without being seen, diagnosis, occupying a bed, treatment and lab tests, admission and boarding processes, and exiting the ED.

\section{DEA MODELS}

There are various DEA models that have been developed to calculate efficiency. In the healthcare sector, the use of the variable returns to scale (VRS) measure (also known as BCC model which is named after Banker, Charnes, and Cooper (1984)) is recommended for evaluating efficiency (Harrison 2005; Osei, D'Almeida, and George 2005), since the performance of healthcare services is not always linear. Considering that most healthcare facilities aim to achieve a higher level of service for the patients by using fewer resources (e.g., the number of beds, the number of staff, etc.), the BCC input-oriented model is well-suited for this research (see Appendix A for the BCC model).

\section{EXPERIMENTS AND ANALYSIS}

The different ED operation alternatives (called DMUs) used in this study have been generated by the ED simulation model subject to the available budget. In order to control the feasible alternatives considered in this research the number of beds are kept within 53 to 54 because the number of beds is determined by the population size. The results from Table 5 indicate that (DMU1, DMU 4, DMU10, DMU11, DMU12, DMU17, DMU20, DMU26, DMU27, and DMU28\} operate efficiently. Specifically, those DMUs are taken as global benchmarks for inefficient DMUs. On the other hand, there is a need to investigate the inefficient DMUs further to reduce the wasted resources. An efficient ED should have shorter patient waiting time for similar operation services and should be able to have better utilization of resources. To deal with ED resource combination variations, a benchmarking approach based on DES and DEA can find more reliable benchmarks for inefficient DMUs. Therefore, the mixed method finds DMUs which perform well. 
Weng, Tsai, Wang, Chang, and Gotcher

Table 5: Different resource allocation operation alternatives in ED

\begin{tabular}{|c|c|c|c|c|c|c|c|}
\hline & PHs & Nurse & Bed & AUP & $\mathbf{A U N}$ & APWT & Efficiency \\
\hline DMU1 & $9\left(2^{a}, 4^{b}, 3^{c}\right)$ & $8(2,3,3)$ & 53 & $61 \%$ & $69 \%$ & 13.31 & 1 \\
\hline DMU2 & $9(2,4,3)$ & $8(2,3,3)$ & 53 & $61 \%$ & $69 \%$ & 13.89 & 0.99 \\
\hline DMU3 & $9(2,4,3)$ & $8(2,3,3)$ & 53 & $61 \%$ & $69 \%$ & 13.42 & 0.99 \\
\hline DMU4 & $9(3,3,3)$ & $8(2,3,3)$ & 53 & $61 \%$ & $69 \%$ & 13.31 & 1 \\
\hline DMU5 & $9(1,4,4)$ & $8(2,3,3)$ & 53 & $61 \%$ & $69 \%$ & 173.68 & 0.93 \\
\hline DMU6 & $9(2,5,2)$ & $8(2,3,3)$ & 53 & $61 \%$ & $69 \%$ & 30.45 & 0.94 \\
\hline DMU7 & $9(3,4,2)$ & $8(2,3,3)$ & 53 & $61 \%$ & $69 \%$ & 30.45 & 0.94 \\
\hline DMU8 & $9(2,4,3)$ & $8(1,4,3)$ & 53 & $61 \%$ & $69 \%$ & 60.2 & 0.93 \\
\hline DMU9 & $9(2,4,3)$ & $8(2,4,2)$ & 53 & $61 \%$ & $69 \%$ & 27.49 & 0.95 \\
\hline DMU10 & $9(2,4,3)$ & $8(3,3,2)$ & 53 & $61 \%$ & $78 \%$ & 30.45 & 1 \\
\hline DMU11 & $8(2,3,3)$ & $8(2,3,3)$ & 53 & $69 \%$ & $69 \%$ & 13.31 & 1 \\
\hline DMU12 & $8(2,4,2)$ & $8(2,3,3)$ & 53 & $69 \%$ & $69 \%$ & 30.42 & 1 \\
\hline DMU13 & $9(2,4,3)$ & $9(3,3,3)$ & 53 & $61 \%$ & $61 \%$ & 13.49 & 0.99 \\
\hline DMU14 & $9(2,4,3)$ & $9(2,4,3)$ & 53 & $61 \%$ & $61 \%$ & 13.31 & 1 \\
\hline DMU15 & $9(2,4,3)$ & $8(3,2,3)$ & 53 & $61 \%$ & $61 \%$ & 27.91 & 0.92 \\
\hline DMU16 & $9(2,4,3)$ & $8(2,4,2)$ & 53 & $61 \%$ & $69 \%$ & 27.49 & 0.95 \\
\hline DMU17 & $9(2,4,3)$ & $8(2,3,3)$ & 54 & $61 \%$ & $69 \%$ & 13.31 & 1 \\
\hline DMU18 & $9(2,4,3)$ & $8(2,3,3)$ & 54 & $61 \%$ & $69 \%$ & 13.89 & 0.99 \\
\hline DMU19 & $9(2,4,3)$ & $8(2,3,3)$ & 54 & $61 \%$ & $69 \%$ & 13.42 & 0.99 \\
\hline DMU20 & $9(3,3,3)$ & $8(2,3,3)$ & 54 & $61 \%$ & $69 \%$ & 13.31 & 1 \\
\hline DMU21 & $9(1,4,4)$ & $8(2,3,3)$ & 54 & $61 \%$ & $69 \%$ & 173.68 & 0.93 \\
\hline DMU22 & $9(2,5,2)$ & $8(2,3,3)$ & 54 & $61 \%$ & $69 \%$ & 30.45 & 0.94 \\
\hline DMU23 & $9(3,4,2)$ & $8(2,3,3)$ & 54 & $61 \%$ & $69 \%$ & 30.45 & 0.94 \\
\hline DMU24 & $9(2,4,3)$ & $8(1,4,3)$ & 54 & $61 \%$ & $69 \%$ & 60.2 & 0.93 \\
\hline DMU25 & $9(2,4,3)$ & $8(2,4,2)$ & 54 & $61 \%$ & $69 \%$ & 27.49 & 0.95 \\
\hline DMU26 & $9(2,4,3)$ & $8(3,3,2)$ & 54 & $61 \%$ & $78 \%$ & 30.45 & 1 \\
\hline DMU27 & $8(2,3,3)$ & $8(2,3,3)$ & 54 & $69 \%$ & $69 \%$ & 13.31 & 1 \\
\hline DMU28 & $8(2,4,2)$ & $8(2,3,3)$ & 54 & $69 \%$ & $69 \%$ & 30.42 & 1 \\
\hline DMU29 & $9(2,4,3)$ & $9(3,3,3)$ & 54 & $61 \%$ & $61 \%$ & 13.49 & 0.88 \\
\hline DMU30 & $9(2,4,3)$ & $9(2,4,3)$ & 54 & $61 \%$ & $61 \%$ & 13.31 & 0.88 \\
\hline DMU31 & $9(2,4,3)$ & $8(3,2,3)$ & 54 & $61 \%$ & $61 \%$ & 27.91 & 0.92 \\
\hline DMU32 & $9(2,4,3)$ & $8(2,4,2)$ & 54 & $61 \%$ & $69 \%$ & 27.49 & 0.95 \\
\hline
\end{tabular}

Note: $a / b / c$ is Night shift/Day shift/Evening shift 


\section{Weng, Tsai, Wang, Chang, and Gotcher}

In summary, our approach consolidates the benchmarking sets and provides better references when ED efficiency is considered. From a managerial perspective, this may provide hospital administrators with a relatively fast method to determine which operation alternative perform better across the various alternatives. This information may be used to determine the use and allocation of resources such as deployment of staff and equipment and may also have employee training and process management implications for employees. For example, a very efficient department may be analyzed to develop training programs for hospital employees so they may perform more efficiently using standard methods and processes.

\section{CONCLUSIONS AND FUTURE RESEARCH}

In this paper we present a mixed method combing DES and DEA models to identify the best performing operations across multiple alternatives. The efficiency of DMUs across multiple alternatives allows for a richer benchmarking analysis. We then demonstrate the proposed method on data supplied by a large teaching hospital center in Taiwan. The benchmarks identified by the proposed approach can be used by less efficient units as a benchmark in improving their efficiency. Finally, the results indicate that the proposed method can generate better benchmarks which consistently perform well over time. Future work includes further investigation into the input and output factors used in the model. Additionally, sensitivity analysis should be performed to determine which factors have the most impact. This will be of benefit in determining where each administrator should spend resources to improve performance the most.

\section{ACKNOWLEDGEMENT}

This research was supported by the National Science Council in Taiwan under funding support NSC992221-E-029-016- "A Large Scale Distributed Simulation Model of Regional Healthcare Real-Time System" and funding suport TCVGH-T1007807 by Taichung Veterans General Hospital and Tunghai University "For Improvement ED Crowding to Use System Simulation for Modeling ED Operations".

\section{A BCC MODEL}

In the BCC input-oriented model, there are 32 DMUs in this paper and each DMU has $s$ outputs and $m$ inputs ( $\mathrm{s}=3$ and $\mathrm{m}=3$ ). Using $\mathrm{DMU}_{0}$ as an example, the model is:

$$
\begin{aligned}
& \operatorname{Max} \theta_{0}=\sum_{j=1}^{m} u_{j} y_{j 0}+u_{0} \\
& \text { s.t } \sum_{\mathrm{i}=1}^{\mathrm{s}} v_{i} x_{i 0}=1 \\
& \sum_{j=1}^{m} u_{j} y_{j k}-\sum_{i=1}^{s} v_{i} x_{i k}+u_{0} \leq 0 \\
& v_{i} \geq 0, u_{j} \geq 0, u_{0} \text { is free in sign }
\end{aligned}
$$

where $\theta_{0}$ is the efficiency score for $\mathrm{DMU}_{0}$ that is evaluated, $x_{\mathrm{i} 0}$ is the vector of input at $\mathrm{DMU}_{0}, y_{\mathrm{j} 0}$ is the vector of output at $\mathrm{DMU}_{0}, x_{\mathrm{ik}}$ is the actual amount of input $i$ used by $\mathrm{DMU}_{k}, y_{\mathrm{jk}}$ is the actual amount of output $j$ produced by $\mathrm{DMU}_{k}$, and $u$ and $v$ are the weights attached to inputs and outputs. If $\mathrm{DMU}_{0}$ is efficient, $\theta_{0}$ equals 1 . Otherwise, $\theta_{0}$ is less than 1 .

\section{REFERENCES}

Ackermann, R. J., K. A. Kemle, R. L. Vogel, and R. C. Griffin, Jr. 1998. "Emergency Department Use by Nursing Home Residents." Ann. Emerg. Med. 31(6):749-747. 


\section{Weng, Tsai, Wang, Chang, and Gotcher}

Banker, R., A. Charnes, and W. Cooper. 1984. "Some Models for Estimating Technical and Scale Efficiencies in Data Envelopment Analysis." Management Science 30(9):1078-1092.

Barnes, C. D., and R. K. Laughery. 1998. "Advanced Uses for Micro Saint Simulation Software." InIn Proceedings of the 1998 Winter Simulation Conference, edited by D. J. Medeiros, E. F. Watson, J. S. Carson, and M. S. Manivannan, 271-274. Piscataway, New Jersey: Institute of Electrical and Electronics Engineers, Inc.

Charnes A., W. W. Cooper, and Rhodes E, 1978. "Measuring the Efficiency of Decision Making Units, "European Journal of Operationa Research. 2, 429-444.

Derlet, R. W. 2002, "Overcrowding in Emergency Departments: Increased Demand and Decreased Capacity." Ann. Emerg. Med. 39(4): 430-432.

Duguay, C., and F. Chetouane. 2007. "Modeling and Improving Emergency Department Systems using Discrete Event Simulation." Simulation 83(4):311-319.

Ertay, T., D. Ruan, and U. R. Tuzkaya. 2006. "Integrating Data Envelopment Analysis and Analytic Hierarchy for the Facility Layout Design in Manufacturing Systems.” Information Sciences 176:237262.

Fatovich, D. M., Y. Nagree, and P. Sprivulis. 2005. "Access Block Causes Emergency Department Overcrowding and Ambulance Diversion in Perth." Western Australia Emerg. Med. J. 22(5):351-354.

Grosskopf, S., and V. Valdmanis. 1987. "Measuring Hospital Performance: A Non-Parametirc Approach." Journal of Health Economics 6:89-107.

Grosskopf, S., and V. Valdmanis. 1993. "Evaluating Hospital Performance with Case-Mix Adjusted Outputs." Medical Care 31:525-523.

Harrison, J. P. 2005. "An Efficiency Analysis of Veterans Health Administration Hospitals." Military Medicine 170:607-611.

Hoot, N. R., and Aronsky, D., 2008, "Systematic Review of Emergency Department Crowding: Causes, Effects and Solutions." Ann. Emerg. Med. 52(2):126-136.

Hoot, N.R., L. J. LeBlanc, I. Jones, S. R. Levin, C. Zhou, C. S. Gadd, and D. Aronsky. 2009. "Forecasting Emergency Department Crowding: A Prospective Real-time Evaluation." Journal of the American Medical Informatics Association 16(3):338-345.

Jun, J. B., S. H. Jacobson, and J. R. Swisher. 1999. "Application of Discrete-event Simulation in Healthcare Clinics: A Survey." Journal of Operational Research Society 50:109-123.

Khurma, N., G. M. Bacioiu, and Z. J. Pasek. 2008. "Simulation-based Verification of Lean Improvement for Emergency Room Process." In Proceedings of the 2008 Winter Simulation Conference, edited by S. J. Mason, R. R. Hill, L. Mönch, O. Rose, T. Jefferson, and J. W. Fowler, 1490-1499. Piscataway, New Jersey: Institute of Electrical and Electronics Engineers, Inc.

Komashie, A., and A. Mousavi. 2005. "Modeling Emergency Departments Using Discrete Event Simulation Techniques." In Proceedings of the 2005 Winter Simulation Conference, edited by M. E. Kuhl, N. M. Steiger, F. B. Armstrong, and J. A. Joines, 2681-2685. Piscataway, New Jersey: Institute of Electrical and Electronics Engineers, Inc.

Nunamaker, T. R. 1983. "Measuring Routine Nursing Service Efficiency: A Comparison of Cost Per Patient Day and Data Envelopment Analysis Models." Health Services Research 18:183-205.

Osei, D., S. D'Almeida, and M. O. George. 2005. "Technical Efficiency of Public District Hospitals And Health Centers In Ghana: A Pilot Study." BioMed Central. 27, 1-13.

Oviatt, J., and L. Hollingsworth, 2005. "Understanding Emergency Department Wait Times." Canadian Institute for Health Information. Accessed May 1, 2011. www.cihi.ca.

Sexton, T. R. 1986. The Methodology of Data Envelopment Analysis. San Francisco, CA: American Evaluation Association, Jossey Bass, Inc.

Sherman, H. D. 1984. "Data Envelopment Analysis as a New Managerial Audit Methodology - Test and Evaluation." Auditing - A Journal of Practice and Theory 4:35-53. 


\section{Weng, Tsai, Wang, Chang, and Gotcher}

Shih, F.-Y., M.-H. Ma, S.-C. Chen, H.-P. Wang, C.-C. Fang, R.-S. Shyu, G.-T. Huang, and S.-M. Wang. 1999. "ED Overcrowding in Taiwan: Facts And Strategies." The American Journal of Emergency Medicine 17(2):198-202.

Tavakoli, S., A. Mousavi, and A. Komashie, 2008. "Flexible Data Input Layer Architecture (FDILA) for Quick Response Decision Making Tools in Volatile Manufacturing Systems." In Proceedings of the IEE, ICC'08 mini-conference. 5515-5520. China.

Thanassoulis E. 1993. "A Comparision of Regression Analysis and Data Envelopment Analysis as Alternative Methods for Performance Assessments." The Journal of the Operational Research Society 44:1129-1144.

Twanmoh, J. R., and G. P. Cunningham. 2006. "When Overcrowding Paralyzes an Emergency Department." Manag. Care. 15(6):54-59.

Weiss, S. J., R. Derlet, J. Arndahl, et al. 2004. "Estimating the Degree of Emergency Department Overcrowding in Academic Medical Centers: Results of the National ED Overcrowding Study (NEDOCS)." Acad. Emerg. Med. 11:38-50.

Wilson, G. W., and J. M. Jadlow. 1982. "Competition, Profit Incentives, and Technical Efficiency in the Provision of Nuclear Medicine Services." The Bell Journal of Economics 13:472-482.

Wu, S. D., and R.A. Wysk. 1988. "Multi-pass Expert Control System-A Control/Scheduling Structure for Flexible Manufacturing Cells." Journal of Manufacturing Systems 7(2):107-119.

Yoon, P., I. Steiner, and G. Reinhardt. 2003. "Analysis of Factors Influencing Length of Stay in the Emergency Department." CJEM 5:155-161.

Yurtkuran, A., and E. Emel. 2008. "Simulation Based Decision-making for Hospital Pharmacy Management." In Proceedings of the 2008 Winter Simulation Conference, edited by S. J. Mason, R. R. Hill, L. Mönch, O. Rose, T. Jefferson, J. W. Fowle. 1539-1546., Austin, Texs, USA,.

\section{AUTHOR BIOGRAPHIES}

SHAO-JEN WENG is an Assistant Professor in the Department of Industrial Engineering \& Enterprise Information at Tunghai University. Dr. Weng received his $\mathrm{PhD}$ with Graduate Certificate in Statistics and Preparing Future Faculty Certificate from Arizona State University in 2008. His industrial experience includes Union Pacific in the US and World-Wide Test Technology Inc. in Taiwan. He has authored papers in Health Services and Outcomes Research Methodology and IEEE International Conference on Service Operations and Logistics, and Information publications, as well as serves as reviewer for Health Care Management Science, CRC Press Taylor and Francis Prepublication, International Journal of Operations Research, Computer Standards \& Interfaces, Winter Simulation Conference, Journal of Quality, and Taipei University Business Management Journal. His main areas of interests are in Distributed Decision Support, Distributed Information System, Supply Chain Management, Data Envelopment Analysis, and Hospital Systems.

BO-SHIANG TSAI received his Master's degree from the Department of Industrial Engineering \& Enterprise Information at Tunghai University. His research interests include Data Envelopment Analysis, Simulation Modeling, and Healthcare system.

LEE-MIN WANG is the Head of Emergency Department in the Taichung Veterans General Hospital and an Assistant Professor of Medicine at National Yang-Ming University in Taiwan. His research interests include Disaster Medicine, Emergency Medicine, Critical Care Medicine, Endocrinology, Internal Medicine, and Operations Research.

CHUN-YUEH CHANG is a Medical Doctor of Emergency Department in the Taichung Veterans General Hospital in Taiwan. His research interests include Disaster Medicine, Emergency Medicine, Critical Care Medicine, Endocrinology, and Information Systems. 


\section{Weng, Tsai, Wang, Chang, and Gotcher}

DONALD F. GOTCHER is an Associate Professor of International Business at Tunghai University, Taiwan, R.O.C. His research interests include inter-organizational learning, expatriate business performance, international business culture comparisons, and organizational efficiency. His research has been published in the Journal of World Business, Health Care Management Review, International Journal of Technology Management, and Industrial Marketing Management, among others. 